\title{
MEASUREMENT SYSTEM FOR TRANSFORMER INRUSH CURRENT HIGHER HARMONICS DETERMINATION
}

\author{
SPOLJARIC, Z[eljko]; JERKOVIC, V[edrana] \& STOJKOV, M[arinko]
}

\begin{abstract}
The aim of this paper is to describe the measurement system and procedure for amount determination and fast Fourier analysis of inrush current which occurs during switching of unbiased transformer on electric grid. This current can reach high amounts and threaten transformer isolation, other transformers and consumers in area. Short introduction in problematic of inrush current phenomena will be presented. In paper the correct measurement settings for inrush current wave form acquisition will be given. Analysis of inrush current waveform in purpose of higher harmonic determination will be given and explained. Usage of gained results in purpose of simulation model evaluation will be explained. The usage of measurement system in purpose of identification of other effects which inrush current can cause will be proposed.

Keywords: measurement system, transformer, inrush current, wave form, higher harmonic, identification.
\end{abstract}

\section{INTRODUCTION}

The problem of inrush current phenomena is known from year 1912 when it was mentioned that during switching unloaded transformer on, high current is created. At that time it was not yet possible to determine the amount of this current. Recording of its wave form was also impossible. Inrush current is magnetizing current which occurs during switching unloaded transformer on to electric grid. Amplitude of this current can be between 3 to 40 times higher than nominal rated current of transformer [1]. During this process complete core saturation can occur [2]. Fig. 1 shows that inrush current wave form is highly non-sinusoidal with large content of higher harmonics [3]. This current can cause many problems which are explained in $[1,4,5]$ and will be mentioned latter in paper. The main goal of this paper is to propose a measurement system which can be used

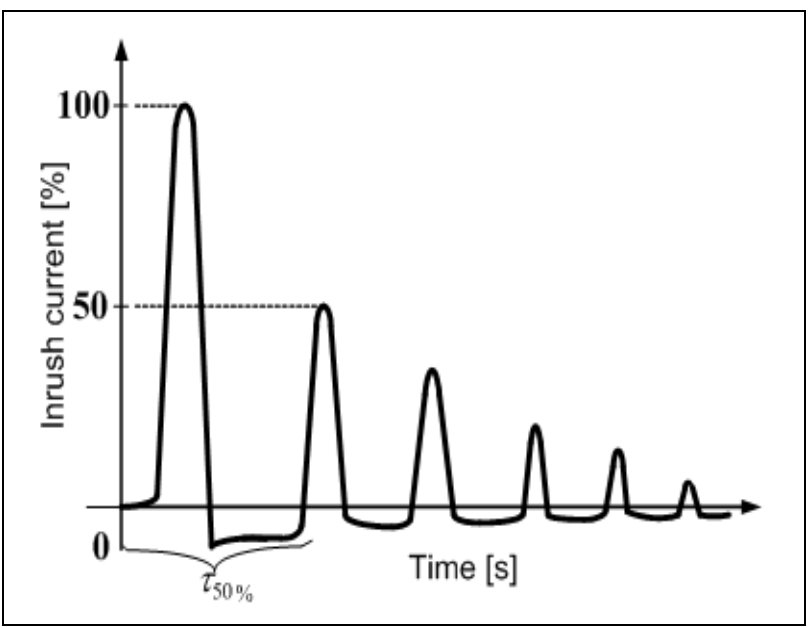

Fig. 1. Typical inrush current waveform [7]

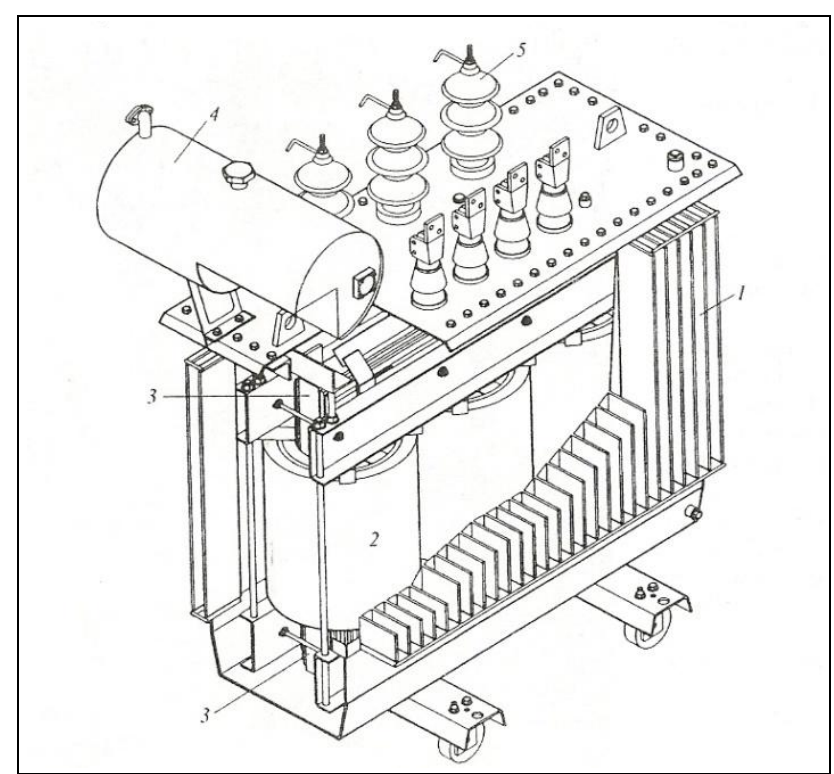

Fig. 2 Distribution transformer (1-kettle, 2-winding, 3-core, 4-oil conservator, 5-isolater) [1]

for fast analysis and evaluation of simulation model for inrush current determination. Every simulation model must be evaluated either with laboratory measurements, field measurements (i.e. measurements in real electric power system) or with numerical calculations. Development of different programs such as Matlab, DigSilent, ATP and LabView has enabled modeling and testing of transformers and electrical machines in purpose of analysis, diagnostics, prediction and prevention of fault stages. In doctoral dissertation [4] brief overview of three phase transformers modeling for inrush current determination is given. This dissertation also provides a measurement of inrush current on distribution transformers (300 kVA and $800 \mathrm{kVA})$, but without measurement system description. Other papers $[6,7]$ describe inrush current analysis in ATP and DigSilent program. Analyses are made on real distribution transformers used in electric power system. In [8] simple modeling of transformer for different examination stages in Matlab is presented. Some analytical calculations are given in [10, 11 and 12]. It is important to mention that analytical calculations have precision of $\pm 40 \%$. Overview of some frequently used analytical methods will be given further. In this paper possibilities for inrush current harmonic analysis in DasyLab and Matlab will be given. Simulation model of system for distribution transformer inrush current analysis is a part of doctoral dissertation. Modeled distribution transformer is shown in Fig. 2. Measurement system will provide evaluation of maximal inrush current amount, its duration as well as amount of higher 


\begin{tabular}{|l|c|c|c|c|c|}
\hline$S_{\mathrm{n}}[\mathrm{MVA}]$ & 0.5 & 1 & 5 & 10 & 50 \\
\hline $\boldsymbol{I}_{\mathrm{u} \max } / \boldsymbol{n}$ & 15 & 14 & 10 & 10 & 9 \\
\hline $\boldsymbol{\tau}_{\mathbf{5 0 \%}}[\mathrm{s}]$ & 0.16 & 0.2 & 1.2 & 5 & 72 \\
\hline
\end{tabular}

Tab. 1. Values and duration time of inrush current [1]

harmonics. Information about necessary measurement equipment and its adjusting to achieve reliable results will be shown. It is important to mention that analysis are made on $250 \mathrm{kVA}$ distribution transformer $(20 / 0.4 \mathrm{kV})$ inelectric power system with data provided by protection relay REF54x which can be used for inrush current waveform recording and further harmonic and amount analysis [9]. As mentioned, inrush current can be evaluated analytically. The values of maximum inrush current amount in dependence of nominal current value and it duration is given in Tab. 1 .

\section{ANALYTICAL CALCULATIONS}

Specht gives one of the first analytical calculations for determination of maximum inrush current amount [11]:

$$
\begin{aligned}
i= & -\frac{\sqrt{2} E X}{z^{2}}\left[\frac{R}{X} \sin (\omega t)-\cos (\omega t)+\right. \\
& +e^{-\left(\frac{R}{X}\right)(\omega t+\theta)}\left(\frac{R}{X} \sin \theta+\cos \theta\right)
\end{aligned}
$$

where $E$ is source voltage, $X$ is system and transformer reactance, $R$ is system and transformer winding resistance, $Z$ is system and transformer impedance. The angle $\theta$ is determined by following equation [11]:

$$
\theta=\cos ^{-1}\left(B_{s}-B_{r}-B_{m}\right) / B_{m}
$$

where $B_{\mathrm{s}}$ is flux density of completely saturated core, $\mathrm{B}_{\mathrm{r}}$ is residual flux density, $B_{\mathrm{m}}$ is maximum flux density of transformer excited to its rated voltage. Holcomb gives the improved version of Specht's equation which can determine inrush current wave form and amount in each cycle as current decreases with time [12]:

$$
\begin{aligned}
& i=\frac{\sqrt{2} E}{\sqrt{R^{2}+\omega^{2} L^{2}}}[\sin (\omega t-\psi)- \\
& e^{-R / L\left(t-\frac{\theta_{s n}}{\omega}\right)} \cdot \sin \left(\theta_{s n}-\psi\right)
\end{aligned}
$$

where $\psi$ is phase angle between voltage and current vector determined with equation:

$$
\psi=\operatorname{tg}^{-1}\left(\frac{L}{R}\right)
$$

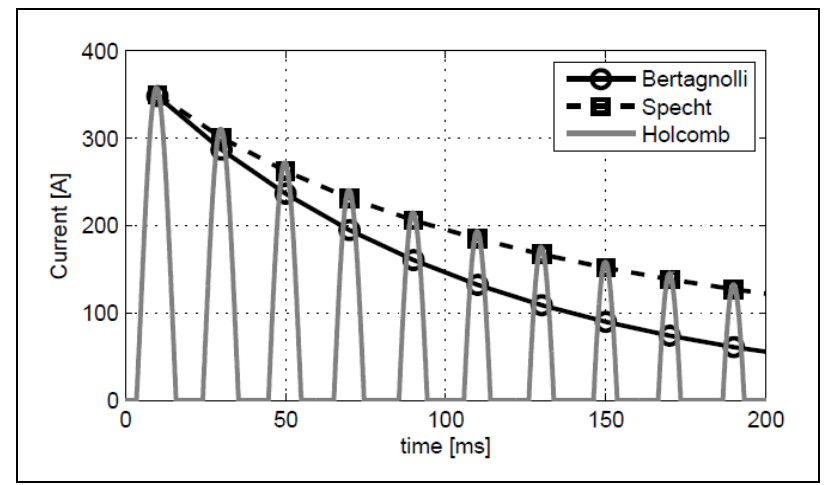

Fig. 3. Comparison of analytical calculations [7] and $\theta_{\mathrm{sn}}$ is angle for each cycle determined with equation (5) where $B_{\mathrm{sn}}$ is residual flux density for each cycle [12]:

$$
\cos \theta_{s n}=\left(B_{m}+B_{r n}+B_{s}\right) / B_{m}
$$

Bertagnolly gives the simplest equation in [13] for fast calculation of inrush current maximal amount. The comparison of mentioned analytical calculations can be found in [4] and is presented in Fig. 3

\section{INRUSH CURRENT EFFECTS}

There are many known problems which inrush current causes and they are stated and elaborated in numerous literatures [14, 15, 16 and 17]. Some of most relevant problems could be stated as follows:

1. If transformer is frequently switching, inrush current can cause the isolation brake because random switching could hit the moment when inrush current has maximal value (this is the moment when switch occurs in time when phase voltage is equal to zero).

2. Even bigger problem arises from higher harmonics in inrush current waveform. These harmonics can cause overvoltages and resonance appearances trough system effecting the other transformers and consumers of electrical energy. Effects of higher harmonic influence are given in [18].

3. Special problem occurs if large number of transformer is being switched on grid after break in electric energy supply because of appearance of higher harmonics.

4. Higher harmonics in inrush current can cause many problems after switching transformers in industrial facilities (supply voltage $6 \mathrm{kV}$ ).

5. Mutual effect occurs if transformer is being switched on bus where other transformers are already switched. Disturbances caused by switched transformer are transferred to other transformers and consumers in the area.

It is important to mention that inrush current peeks are higher for smaller transformers, but duration of this phenomenon (time necessary for inrush current drop to $50 \%$ of its value) is longer for larger transformers (Tab. 1) [18]. Accurate estimation of second and fifth harmonic is very important because the protection of transformer depends on amount of these harmonics which need to be set in protection relays. Mentioned harmonics in modern transformers could have very low amplitude which cannot be registered by relay protection. Measurements of these harmonics for different transformer switch times will be specially emphasized.

\section{MEASUREMENT SYSTEM}

As pointed out in introduction, measurement system for inrush current amount and higher harmonic determination will be used for evaluation of simulation model for transformer inrush current analysis as part of doctoral dissertation. The main goal was to create a system for reliable measurement of higher harmonic detection in inrush current waveform for laboratory three 


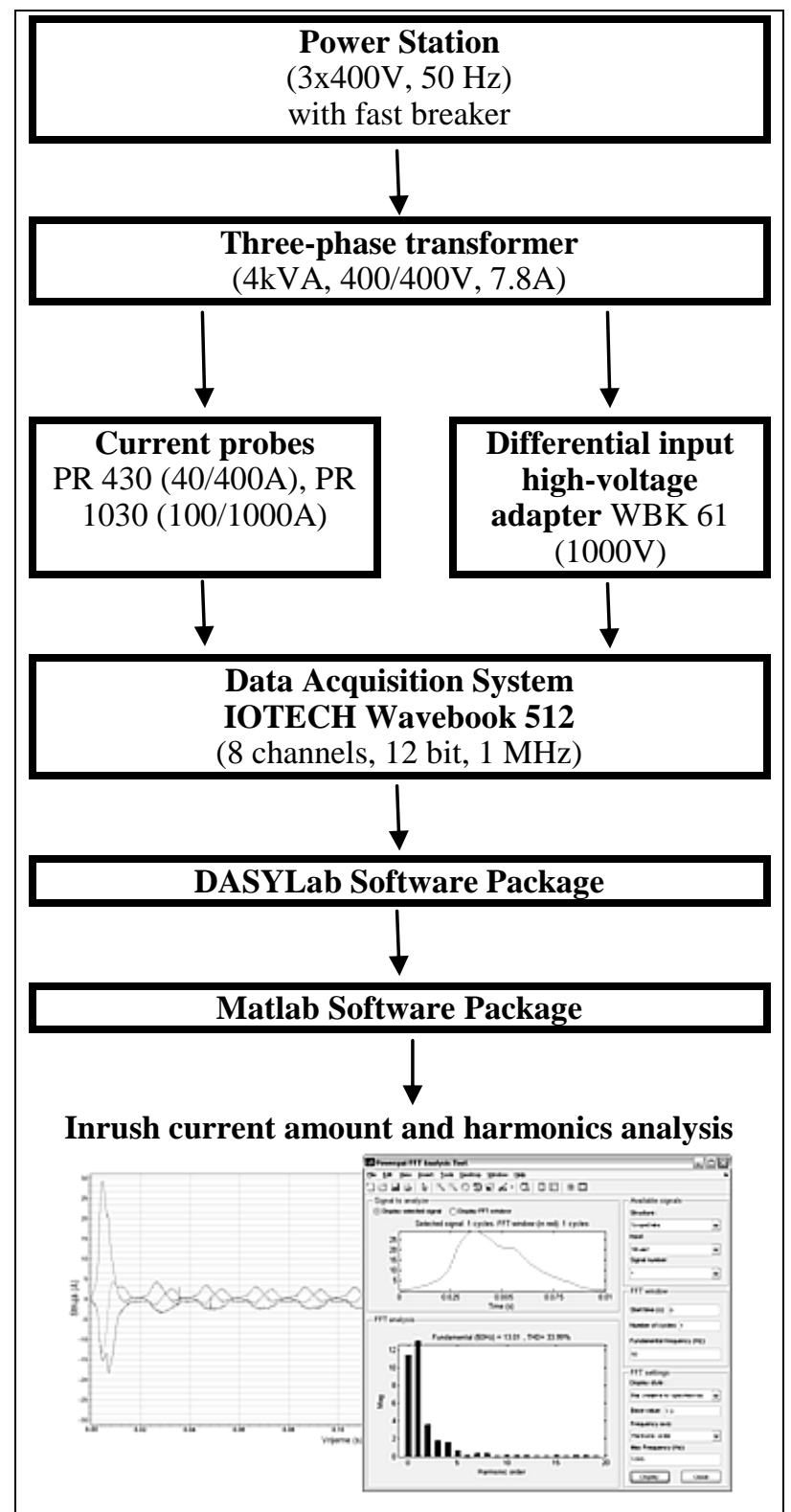

Fig 4. Measurement system for transformer inrush current higher harmonic determination

phase transformer ( $4 \mathrm{kVA})$ whose data are given in Tab. 2. Measurement system is presented in Fig. 4. and it consists from three phase power station (maximum power $12 \mathrm{kVA}$ ) with fast three phase breaker, test transformer, current probes for three phases (maximum current $1000 \mathrm{~A}$ ), differential input high-voltage adapter (maximum voltage $1000 \mathrm{~V}$ ), data acquisition system Iotech Wavebook 512 (8 channels, $1 \mathrm{MHz}$ ), DasyLab software package for data recording and analysis and Matlab software package for inrush current harmonic analysis. DasyLab software is specially designed for data acquisition using Iotech measurement equipment. Ioteh measurement data acquisition card has 8 input analog channels with sampling rate $1 \mu \mathrm{s} /$ channel. Communication with PC is trough parallel port. In our case 6 channels are in use. Three channels are used for current recording and three channels are used for voltage recording as shown in Fig. 5. In Fig. 5 first channel is designated with " 0 " and last with number " 5 ". Current probes have measurement range up to $40 \mathrm{~A}$ (resolution

\begin{tabular}{|c|c|c|c|c|c|c|c|}
\hline $\begin{array}{c}S_{\mathrm{n}} \\
{[\mathrm{kVA}]}\end{array}$ & $\begin{array}{c}U_{1 \mathrm{n}} \\
{[\mathrm{V}]}\end{array}$ & $\begin{array}{c}U_{2 \mathrm{n}} \\
{[\mathrm{V}]}\end{array}$ & $\begin{array}{c}I_{1 \mathrm{f}} \\
{[\mathrm{A}]}\end{array}$ & $\begin{array}{c}I_{2 \mathrm{f}} \\
{[\mathrm{A}]}\end{array}$ & $\begin{array}{c}U_{1 \mathrm{f}} \\
{[\mathrm{V}]}\end{array}$ & $\begin{array}{c}U_{2 \mathrm{f}} \\
{[\mathrm{V}]}\end{array}$ & $\begin{array}{c}\text { winding } \\
\text { connect } \\
\text { ion }\end{array}$ \\
\hline 4 & 400 & 400 & 7.8 & 7.8 & 231 & 231 & $\mathrm{Yy} 0$ \\
\hline $\begin{array}{c}I_{0} \\
{[\mathrm{~A}]}\end{array}$ & $\begin{array}{c}P_{0} \\
{[\mathrm{~W}]}\end{array}$ & $\cos \varphi_{0}$ & $\begin{array}{c}P_{\mathrm{j}} \\
{[\mathrm{W}]}\end{array}$ & $\begin{array}{c}U_{\mathrm{k}} \\
{[\mathrm{V}]}\end{array}$ & $\begin{array}{c}P_{\mathrm{k}} \\
{[\mathrm{W}]}\end{array}$ & $\begin{array}{c}R_{\mathrm{k}} \\
{[\Omega]}\end{array}$ & $\begin{array}{c}X_{\mathrm{k}} \\
{[\Omega]}\end{array}$ \\
\hline 0.723 & 47.39 & 0.095 & 498.88 & 6.99 & 152.4 & 0.824 & 0.338 \\
\hline$R_{1}$ & $R_{2}$ & $X_{\sigma 1}$ & $X_{\sigma 2}$ & $P_{\mathrm{j}}$ & $R_{\mathrm{m}}$ & $X_{\mathrm{m}}$ & $Z_{\mathrm{k}}$ \\
{$[\Omega]$} & {$[\Omega]$} & {$[\Omega]$} & {$[\Omega]$} & {$[\mathrm{W}]$} & {$[\Omega]$} & {$[\Omega]$} & {$[\Omega]$} \\
\hline
\end{tabular}

$\pm 10 \mathrm{~mA}$ ) or up to $400 \mathrm{~A}$ (resolution $\pm 100 \mathrm{~mA}$ ). In our case measurement range was set to $40 \mathrm{~A}$. Because of measured current conversion in voltage signal, conversion rate is $10 \mathrm{mV} / \mathrm{A}$. Differential input highvoltage adapter (voltage probes) have BNC connector input for connection to Iotech measurement card and two inputs ( $\mathrm{HI}$ and $\mathrm{LO}$ ) for measured voltage signal. Each input has serial resistance $(10 \mathrm{M} \Omega)$ for damping input signal in rate 200:1. This resistance limits current to 100 $\mu \mathrm{A}$ if voltage input is maximal $1000 \mathrm{~V}$. After adjusting measurement modules for analog input (designated as A/D in Fig. 5) and modules for data recording, data reading and data presentation (chart recorder), recording procedure is:

1. Set source voltage at power station to $230 \mathrm{~V}$ (phase voltage).

\section{Start data acquisition in DasyLab software package.}

3. In desired switch time activate fast breaker and connect unbiased transformer to electric grid.

4. Choose different switch times of transformer for inrush current phenomena analysis (five different switching times are chosen).

5. Recorded data are saved and prepared for analysis in Matlab for exact inrush current amount determination and using FFT analysis using Matlab function for fast Fourier analysis.

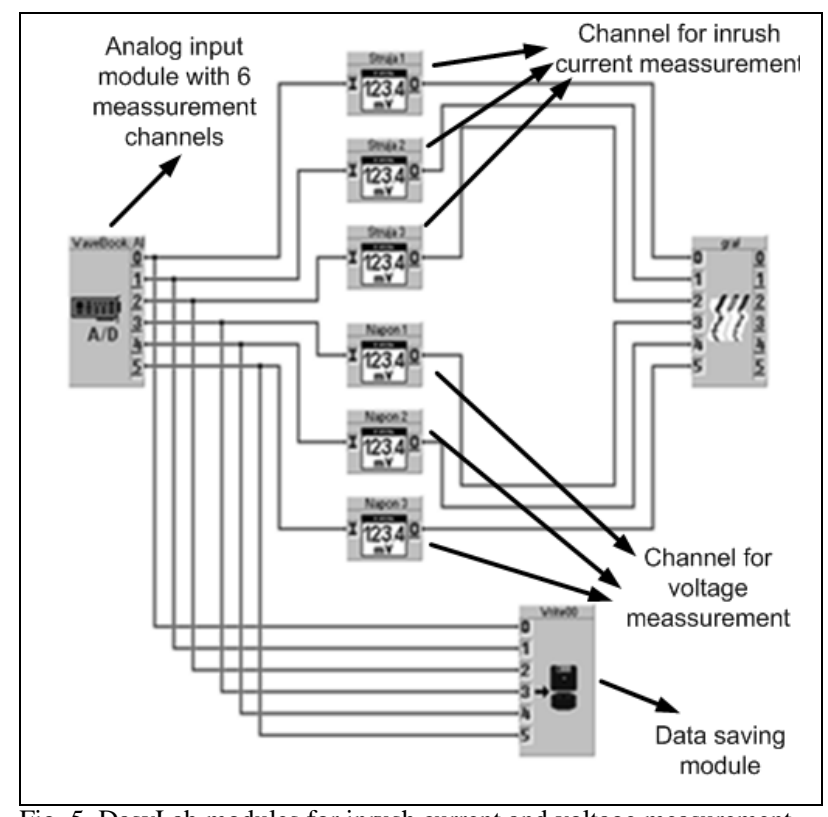

Fig. 5. DasyLab modules for inrush current and voltage measurement 


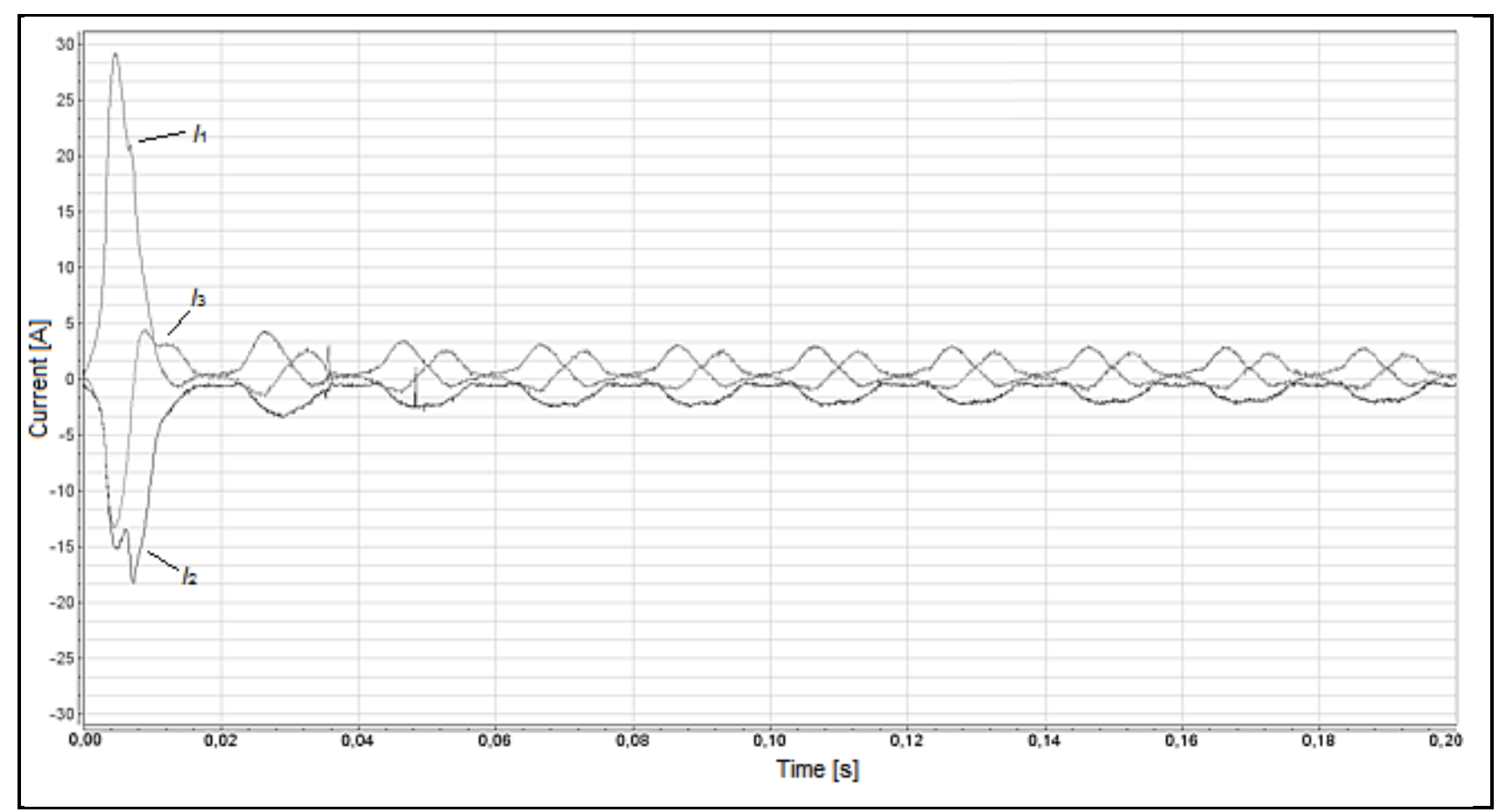

Fig. 6. Measured currents in all three phases in fifth measurement with maximum inrush current appearance in DasyLab program

\section{MEASUREMENT RESULTS}

As mentioned in introduction, measurement system for inrush current amount and higher harmonic determination will be used for evaluation of simulation model for transformer inrush current analysis as part of doctoral dissertation. Five measurements are made for different switch time of transformer. The maximum inrush current appears in fifth measurement when voltage in phase 1 passes trough zero (Fig. 6). It can be seen that inrush current waveform has large and long lasting DC component and is rich with harmonics and large peek values at the beginning (in our case 3.7 times bigger than nominal current). The current in phase 1 for fifth measurement is transferred in Matlab program as shown in Fig. 7, so harmonic analysis could be performed. In Tab. 3 readings of three phase current and voltage are shown for different time in case of maximum inrush current appearance (fifth measurement). It is obvious that maximum current $(29.19 \mathrm{~A})$ is reached in $4.89 \mathrm{~ms}$ after switching in phase 1 . In other phases current reaches smaller amounts. In Tab. 4 readings of maximum inrush current appearance and inrush current duration for different switch time are given. $\tau_{50 \%}$ is time necessary for inrush current drop to $50 \%$ of its maximum value. This time is longer and could reach few minutes for larger transformers. In our case this time is

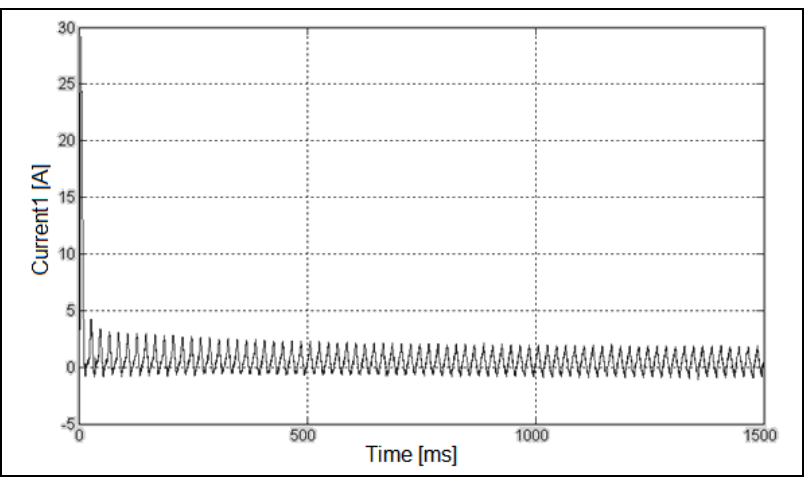

Fig. 7. Inrush current in phase 1 for fifth measurement in Matlab

\begin{tabular}{|c||c|c|c||c|c|c|}
\hline $\begin{array}{c}\text { Time } \\
{[\mathbf{m s}]}\end{array}$ & $\begin{array}{c}\boldsymbol{I}_{\mathbf{1}} \\
{[\mathbf{A}]}\end{array}$ & $\begin{array}{c}\mathbf{I}_{\mathbf{2}} \\
{[\mathbf{A}]}\end{array}$ & $\begin{array}{c}\mathbf{I}_{\mathbf{3}} \\
{[\mathbf{A}]}\end{array}$ & $\begin{array}{c}\boldsymbol{U}_{\mathbf{1}} \\
{[\mathbf{V}]}\end{array}$ & $\begin{array}{c}\boldsymbol{U}_{\mathbf{2}} \\
{[\mathbf{V}]}\end{array}$ & $\begin{array}{c}\boldsymbol{U}_{\mathbf{3}} \\
{[\mathbf{V}]}\end{array}$ \\
\hline 0 & 0.53 & -0.66 & 0.13 & 279.1 & 5.2 & -291.0 \\
\hline 4.89 & 29.19 & -15.03 & -13.28 & 15.5 & -257.9 & 150.4 \\
\hline 7.41 & 18.88 & -18.27 & -0.70 & -39.0 & -29.2 & 412.0 \\
\hline
\end{tabular}

Tab. 3. Readings of current and voltage for fifth measurement for all three phases and different time

approximately $10 \mathrm{~ms}$ because measurements are made on laboratory transformer $(4 \mathrm{kVA})$. As mentioned, the maximum current appears in fifth measurement. The most convenient switch time is in moment of maximum voltage in each phase. This is only possible for one phase because when maximum voltage is in phase 1 , in phases 2 and 3 voltages do not have maximum value. Switch in moment of maximum voltage in all three phases is possible only if switch in other two phases happens with time shift. This means that all three phases are not switched in the same time. This way of inrush current reduction is expensive and it is performed only for large transformers with high amounts of inrush current. After recording of inrush current which is shown in Fig. 6 and its transfer to Matlab program (Fig. 7) Fourier harmonics analysis is made. Fourier analysis is made for five measurements and phase where maximum current is reached. Fourier analysis is then performed only for first cycle with maximum value. This is shown in Fig. 8 (graphs a) to e)) where last analysis (Fig. 8, e) is for measurement with maximum inrush current appearance.

\begin{tabular}{|c|c|c|c|}
\hline $\begin{array}{c}\text { Measurement } \\
\text { number }\end{array}$ & $\begin{array}{c}\text { Time } \\
{[\mathbf{m s}]}\end{array}$ & $\begin{array}{c}\text { Current } \\
{[\mathbf{A}]}\end{array}$ & $\begin{array}{c}\boldsymbol{\tau}_{\mathbf{5 0} \%} \\
{[\mathbf{m s}]}\end{array}$ \\
\hline 1 & 10.00 & 10.22 & 11 \\
\hline 2 & 6.82 & 16.66 & 10 \\
\hline 3 & 5.65 & -22.20 & 9.5 \\
\hline 4 & 4.98 & -28.80 & 8.5 \\
\hline 5 & 4.89 & 29.19 & 9 \\
\hline
\end{tabular}

Tab. 4.Readings of maximum inrush current appearance and duration of inrush current for five different switch time of transformer 


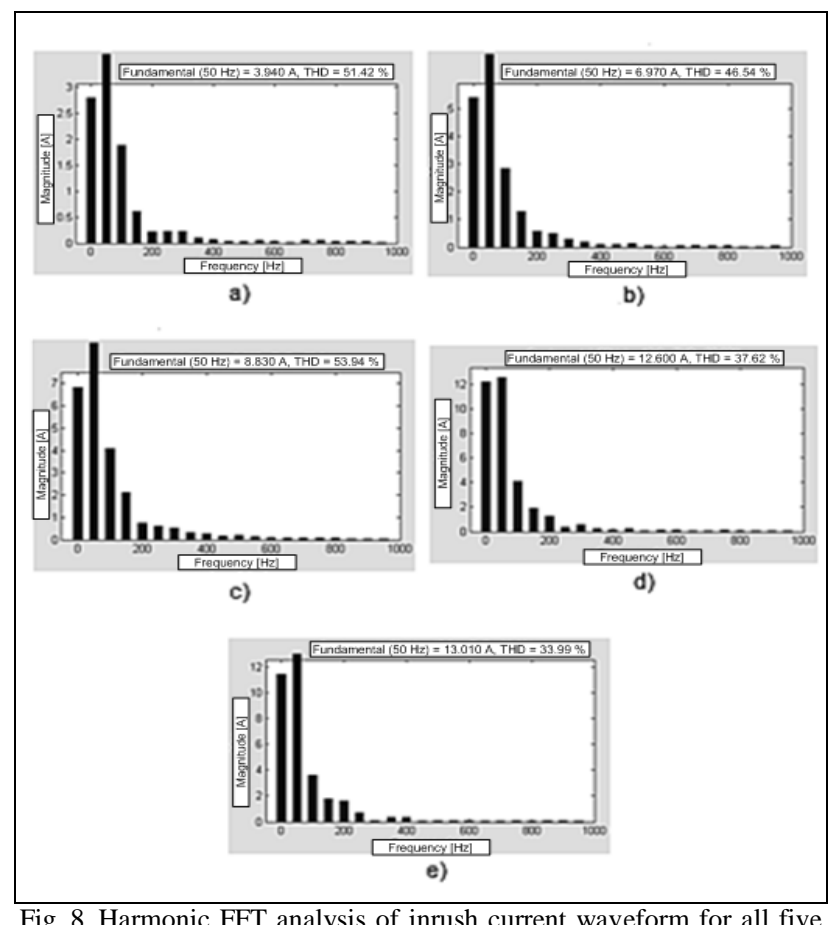

Fig. 8. Harmonic FFT analysis of inrush current waveform for all five measurements

In Tab. 5 readings for first 20 harmonics for all five measurements are given. These readings show that, beside the fundamental harmonic, most influence on inrush current amount have following harmonics: second, third, fourth, fifth, sixth, seventh, eight, tenth and eleventh harmonic. Other harmonics have negligible influence. For transformer protection and security the most important is accurate estimation of second and fifth harmonic because protective relays are adjusted to values of those harmonics. As explained in [18] for modern transformers values of second harmonic during inrush current phenomenon and fifth harmonic during overexcitation could be very low due to magnetic properties of core lead to relay malfunction. It is also important to notice that presence of higher harmonics does not necessary indicate inrush current appearance. Fifth harmonic may also be present in internal fault currents. Speed acting of protective relay depends on duration of first cycle of inrush current. In this time relay must recognize inrush current appearance or it must act if fault is caused by other source. Problem for relay proper action may also cause the reduced amount of second harmonic when maximum inrush current appears (voltage passes trough zero) as it happened in fifth measurement (Tab. 5, e). This effect is presented in Tab. 6 where amplitude ratio of second harmonic and fundamental frequency signal is given in percentages. It is visible that second harmonic amount drops $20 \%$ if a) and e) measurement is compared. First measurement is the case of minimum inrush current appearance and fifth measurement is the case when maximum inrush current appears. Amount of second harmonic in inrush current waveform depends of magnetizing characteristic of iron core. If saturation flux density is lower, amount of second harmonic will be higher. It could be taken into consideration that inrush phenomena occurs if drop of second harmonic amplitude is $20 \%$ or higher then fundamental frequency amplitude. Relay protection of transformer in this case should restrain from acting.

\begin{tabular}{|c|c|c|c|c|c|}
\hline \multirow{2}{*}{$\begin{array}{l}\text { Harmonic } \\
\text { frequency }\end{array}$} & \multicolumn{5}{|c|}{ Inrush current harmonics [A] } \\
\hline & a) & b) & c) & d) & e) \\
\hline $0 \mathrm{~Hz}$ (DC): & 2.79 & 5.40 & 6.82 & 12.19 & 11.41 \\
\hline $50 \mathrm{~Hz}$ (Fnd): & 3.94 & 6.97 & 8.83 & 12.60 & 13.01 \\
\hline $100 \mathrm{~Hz}(\mathrm{~h} 2):$ & 1.88 & 2.83 & 4.09 & 4.10 & 3.60 \\
\hline $150 \mathrm{~Hz}(\mathrm{~h} 3):$ & 0.62 & 1.31 & 2.12 & 1.88 & 1.79 \\
\hline $200 \mathrm{~Hz}(\mathrm{~h} 4):$ & 0.21 & 0.59 & 0.75 & 1.25 & 1.62 \\
\hline $250 \mathrm{~Hz}$ (h5): & 0.24 & 0.49 & 0.60 & 0.33 & 0.72 \\
\hline $300 \mathrm{~Hz}$ (h6): & 0.22 & $\mathbf{0 . 3 1}$ & 0.51 & 0.54 & 0.12 \\
\hline $350 \mathrm{~Hz}(\mathrm{~h} 7):$ & $\mathbf{0 . 1 0}$ & 0.18 & $\mathbf{0 . 3 0}$ & 0.22 & 0.32 \\
\hline $400 \mathrm{~Hz}(\mathrm{~h} 8):$ & 0.06 & $\mathbf{0 . 1 0}$ & 0.26 & 0.15 & 0.31 \\
\hline $450 \mathrm{~Hz}$ (h9): & 0.03 & 0.09 & 0.16 & 0.20 & 0.05 \\
\hline $500 \mathrm{~Hz}$ (h10): & $\mathbf{0 . 0 3}$ & 0.12 & 0.20 & 0.04 & 0.08 \\
\hline $550 \mathrm{~Hz}$ (h11): & 0.06 & 0.06 & 0.11 & 0.09 & 0.09 \\
\hline $600 \mathrm{~Hz}$ (h12): & 0.04 & 0.02 & 0.10 & 0.07 & 0.08 \\
\hline $650 \mathrm{~Hz}$ (h13): & 0.00 & 0.05 & 0.06 & 0.02 & 0.06 \\
\hline $700 \mathrm{~Hz}$ (h14): & 0.05 & 0.08 & 0.04 & 0.06 & 0.04 \\
\hline $750 \mathrm{~Hz}$ (h15): & 0.05 & 0.04 & 0.05 & 0.07 & 0.09 \\
\hline $800 \mathrm{~Hz}$ (h16): & 0.02 & 0.03 & 0.04 & 0.06 & 0.04 \\
\hline $850 \mathrm{~Hz}$ (h17): & 0.03 & 0.03 & 0.04 & 0.01 & 0.06 \\
\hline $900 \mathrm{~Hz}$ (h18): & 0.04 & 0.03 & 0.02 & 0.05 & 0.09 \\
\hline $950 \mathrm{~Hz}$ (h19): & 0.01 & 0.03 & 0.02 & 0.02 & 0.04 \\
\hline THD (\%): & 51.42 & 46.54 & 53.94 & 37.62 & 33.99 \\
\hline
\end{tabular}

Tab. 5. Amount readings for 20 harmonics for all five measurements

Usually if low levels of harmonics appear relay protection should be activated and if amount of harmonics is high relay protection should be restraint from acting because of inrush appearance. In Fig. 8 and in Tab. 5 data about Total Harmonic Distortion parameter (THD) in percentages are also given. For preformed measurements this parameter is between $33 \%$ and $51 \%$ and gives information how much signal power deviates from fundamental harmonic. This deviation for inrush phenomena is high as visible from measured data.

\begin{tabular}{|c|c|c|c|c|c|}
\hline Measurement & a) & b) & c) & d) & e) \\
\hline $50 \mathrm{~Hz}$ (Fnd): & 3.94 & 6.97 & 8.83 & 12.60 & 13.01 \\
\hline $100 \mathrm{~Hz}$ (h2): & 1.88 & 2.83 & 4.09 & 4.10 & 3.60 \\
\hline (h2/Fnd) $100 \%$ & 47.72 & 40.60 & 46.32 & 32.54 & 27.67 \\
\hline
\end{tabular}

Tab. 6. Amplitude ratio of second harmonic and fundamental frequency signal

\section{CONCLUSION}

This paper proposes a measurement system for inrush current determination and harmonics analysis. Proposed system is used for evaluation of simulation model for inrush current analysis as part of doctoral dissertation. Evaluation will be performed for inrush current maximum value appearances and harmonics amount for distribution transformers (10/0.4 kV and 20/0.4 kV). This type of evaluation is necessary because the analytical calculations which are described in chapter two can have accuracy of $\pm 40 \%$ which is not reliable for inrush current 
amount determination. Also some calculations do not have possibility for detailed harmonics evaluation which is crucial for protection relay adjustment. In paper detailed measurement system for reliable measurement of inrush current appearance is shown. Measurement system uses modern data acquisition card with high sampling rate which enables possibility for detailed harmonics analysis of recorded signal. Measurement system also provides possibility for different switch time choice because the amplitude of inrush current depends of voltage amount in time of switch for each phase of transformer. Five different switch times were recorded. Last measurement is the case with maximum inrush current appearance. All measurements were done by using DasyLab program and harmonic analysis is then made in Matlab program. Harmonic analysis is made for first twenty harmonics. Measurements show amount of harmonics in inrush current waveform. It can be seen that inrush current is rich with harmonics. It could be concluded that there are several factors that have influence on inrush current shape, amplitude and duration. These factors are: size of transformer, system impedance, magnetic properties of core, which have greater influence if flux density is low, remanence in the core which can be from 1.3 to $1.7 \mathrm{~T}$, moment of transformer switch which was mentioned earlier and way of switch of each transformer phase. The last factor relates to way of switching of three phase transformer. Amplitude of inrush current could be reduced if switch of transformer is done by separate breaker for each phase. In this way each phase does not switch in the same time and enables switching in most convenient moment. Special accent in the paper to determination of amount of second and fifth harmonic is given. These harmonics are crucial for reliable function of transformer protective relays. Special problem causes reduction of second harmonic in worst case scenario when maximum inrush current appears. This reduction can be more than $20 \%$ from fundamental frequency amplitude and can cause improper relay operation. As it can be seen from results this is also case in given measurements. Modern transformers due to the magnetic properties of core can have low amount of second harmonic. Fifth harmonic can also be low due to overexcitation. Relay protection must be able to act in time of one full cycle of inrush current. In this cycle it is necessary to determine if disturbance is caused by inrush current, overexcitation, external or internal faults. Knowing the expected values of inrush current amplitude and harmonics amount for different power ranges of transformers used in distribution and transmitting systems provides more reliable and accurate settings of protective relays. As shown, generally low levels of harmonics indicate that internal or external fault occurs and high level of harmonics indicates inrush appearance. On the other hand, there are some cases where this assumption is not correct as it was explained before.

Further research will be performed in case of transformer testing for different ground connections on inrush current amplitude and harmonics amount. There is significant difference if transformer neutral point is directly grounded, isolated, or grounded over active resistance or dumping inductance. Also there is influence of winding connection of transformer. Influence of switching unloaded transformer on bus to tested transformer when they work in parallel state will be examined. Significant influence of inrush current to consumers connected to transformer which works in parallel state with switched transformer occurs. Results will be further verified by measured values gained using protective relay REF54x implemented in transformer station $(20 / 0.4 \mathrm{kV})$ and have possibility for inrush current determination, waveform recording and further harmonics analysis.

\section{REFERENCES}

[1] Kelemen, T. (1997). Transformer (Transformator), In Technical Encyclopedia (Tehnička enciklopedija,) HRZ Sv. 13, Podhorsky, R. (Ed), pp. 149-168, HLZ, ISBN 953-6036-50-9, Zagreb, Croatia

[2] Jadric, M.; Francic, B. (1995). Dynamic of Electric Machines (Dinamika elektricnih strojeva), Graphis, ISBN 953-96399-2-1, Zagreb, Croatia

[3] Yacamini R.; Abu-Nasser A. (1986). The Calculation of Inrush Current in Three-phase Transformerss, IEEE Proc. B. Electric Power Applications, Vol. 133, No 1, January 1986., pp 31-40, ISSN : 0143-7038

[4] Chiesa N. (2010). Power Transformer Modeling for Inrush Current Calculacion, Ph.D. Dissertation, Norwegian Univesity of Science and Tehnology, Trondhame, Norway

[5] Winders, J.J. (2002). Power Transformers Principles and Applications, Marcel Dekker, Inc. New York, ISBN: 0-82470766-4, Basel, Switzerland

[6] Maric, P.; Nikolovski, S. \& Baus, Z. (2006).Simulation of 300MVA Transformer Energization in new substation $400 / 110 \mathrm{kV}$ Ernestinovo using ATP-EMTP, Proceedings of EEUG, Hopfner, S. (Ed.), pp. 57-65, Tehnische Universitat Dresden, September 2006., EEUG Committee, Dresden

[7] Spoljaric, Z.; Penic, J.; Valter, Z. (2007). Dynamical Behaviour Analysis of Energetic Transformers using DIgSILENT Program, Annals of DAAAM for 2007 \& Proceedings, October $24-27$, 2007, Zadar, Hrvatska, ISBN: 3-901509-58-5, Katalici, B. (Ed.). pp, 701-702, DAAAM International, Vienna

[8] Valter, Z. (2009). Electrical Machines and Drives in Matlab (Elektricni strojevi i pogoni s Matlabom),University of Osijek, Faculty of Electrical Engineering, ISBN 978-953-6032-07-9, Osijek, Croatia

[9] Crnković D.; Vrandečić N.; Stojkov M. (2010). Transients NoLoad Condition of Power Transformer 20/0.4 kV, Tehnical Gazzete, Vol. 17, No. 2, 2010, pp. 179-183

[10] Specht T.R. (1951). Transformer Magnetizing Inrush Current, AIEE Transactions, Vol. 70, 1951, pp. 323-328

[11] Specht T.R. (1969). Transformer Inrush and Rectifier Transient Currents, IEEE Transactions (Power Aparatures and Systems), Vol. PASS-88, No. 4, 1969, pp. 269-276

[12] Holcomb J.E. (1961). Distribution Transformer Magnetizing Inrush Current, AIEE Transactions (Power Aparatures and Systems) Part III, Vol. 80, No. 57, 1961, pp. 697-702

[13] Bertagnolli G. (2006). Short-Circuit Duty of Power Transformers, $3^{\text {rd }}$ Revised Edition, ABB Management Services Ltd Transformers, Zurich, Switzerland

[14] Shenkman A.L., Transient Analysis of Electric Power Circuits Handbook, Springer, ISBN: 13-978-0-387-28799-7, Dordrecht, Netherland, 2005

[15] Moses P. S.; Masoum M. A. S.; Toliyat H. A. (2011). Impacts of Hysteresis and Magnetic Couplings on Stability Domain of Ferroresonance in Asymmetric Three-Phase Three-Leg Transformer, IEEE Transactions on Energy Conversion, Vol. 26, No. 2, 2011, pp. 581-592, 2011

[16] Tokic A.; Uglesic I; Jakl F. (2003). An Algorithm for Calculation of Low Frequency Transformer Transients, International Conference on Power System Transients IPST, September $28-$ October 2, 2003, New Orleans, Lousiana, USA

[17] Tokic A.; Madzarevic V.; Uglesic I. (2005). Numerical Calculations of Three Phase Transformer Transients, IEEE Transaction on Power Delivery, Vol. 20, No. 4, pp. 2493-2500

[18] Kasztenny B.; Kulidjian A. (2000). An Improved Transformer Inrush Restraint Algorithm Increases Security while Maintaining Fault Response Performance, 53th Annual Conference for Protective Relay Engineers, College station, Texas, April 11-13, 2000 